\title{
A GENEALOGIA EM FOUCAULT
}

RESUMO. Este texto, que tem origem em minha dissertação de mestrado, se propõe discorrer sobre a genealogia enquanto metodologia, conforme proposta por Michel Foucault. Nesta abordagem, a análise arqueológica do discurso é entendida como a base que dá suporte à genealogia, ao propor a descrição do campo como uma rede formada na inter-relação dos diversos saberes ali presentes, que possibilitam a emergência do discurso como o percebemos. Já a abordagem genealógica busca a origem dos saberes através dos fatores que interferem na sua emergência, permanência e adequação ao campo discursivo como elementos incluídos em um dispositivo político que abre as condições para que os sujeitos possam se constituir imersos em determinadas práticas discursivas.

Palavras-chave: genealogia, práticas discursivas, subjetivação.

\section{THE GENEALOGY ON FOUCAULT}

\begin{abstract}
This text, originated from my Master's thesis, aims to dissertate on genealogy as methodology, according to Michel Foucault's proposition. In this approach, the archeological analysis of the speech is understood as the foundation supporting genealogy by suggesting the description of the field as a net formed in the inter-relationship of the several knowledge present, which makes possible the discourse emerge according to our concept. The genealogical approach searches for the origin of the knowledge through the factors interfering in their emergence, maintenance and suitability to the discursive field, as elements included in a political speech opening the conditions to enable the individuals to be immersed in given discursive practices.
\end{abstract}

Key words: genealogy, discursive practices, subjectivity.

Segundo Deleuze (2000), na construção Foucaultiana, o saber, o poder e a constituição de si emergem como a tripla raiz de uma problematização do pensamento. Argumenta ainda o autor que esta teoria é um entendimento sobre o pensar, que se constitui, caracteriza e atualiza, principalmente, pela experimentação e problematização.

A problematização, em decorrência da indução a novas formas de pensar, remete à produção de modos de subjetivação que atravessam e atualizam os saberes e as relações de poder. Cabe salientar que, para Foucault, o de-dentro enquanto constituinte do sujeito é apenas a dobra do de-fora, pois se é o homem que ocupa o papel de sujeito de enunciação, por outro lado, são as práticas discursivas existentes neste contexto que definem as condições de possibilidade para que o enunciado possa surgir e ser validado.

Tal posição pressupõe um movimento contínuo de dentro / de fora - posições que se diferenciam apenas por espaços temporais, num mesmo campo geográfico
- onde os sujeitos e a sociedade, atravessados pelas práticas discursivas, se transformam na continuidade um do outro. Nesse espaço-tempo permanentemente eles realimentam-se através do pensamento que se objetiva, prioritariamente, através do ver e do falar nas práticas discursivas: “(...) cada formação histórica vê e faz ver tudo o que pode em função das suas condições de visibilidades, assim como diz tudo o que pode em função das suas condições de enunciado" (Deleuze, 1998, p. 87).

Ver e falar se definem como formas de exterioridade, porém o pensar realiza-se sob a intrusão de um de-fora mais longínquo que se infiltra no espaço entre o ver e o falar, ou seja, no seu interstício, movimento que é provocado pelas forças em relação. Desta forma, é sempre do de-fora que uma força confere a outras ou recebe delas a sua afetação variável.

Com este entendimento, priorizando a problematização sobre a forma dos enunciados -

* Mestre em Psicologia Social e da Personalidade - PUC-RS.

Agradecimentos à Profa. Dra. Juracy C. Marques, da Faculdade de Psicologia (PUC-RS), por seu estímulo e orientação na elaboração de minha dissertação de mestrado, assim como pela revisão deste artigo, que tem origem naquele trabalho. 
priorização feita em virtude da espontaneidade das palavras em relação às coisas - Foucault desenvolve a analítica interpretativa - denominação sugerida por Rabinow e Dreyfus (1995) - onde investiga a situação presente tendo como foco as práticas de subjetivação.

Para os autores acima, este método busca a análise do que somos, sendo necessários, para isto, movimentos que se materializam como oposição às duas formas de sujeição identificadas: uma que consiste em individuar-nos de acordo com exigências do poder e outra que consiste em prender cada indivíduo a uma identidade sabida e conhecida, bemdeterminada.

Aqui ganha importância o entendimento sobre os modos de objetivação de tais formas de sujeição. Neste sentido, Foucault (2000) define como condição prioritária de materialização o falar, que emerge e se configura através das práticas discursivas, uma vez que:

(...) falar é fazer alguma coisa - algo diferente de exprimir o que se pensa, de traduzir o que se sabe e, também, de colocar em ação as estruturas de uma língua; mostrar que somar um enunciado a uma série preexistente de enunciados é fazer um gesto complicado e custoso que implica condições (...) e comporta regras (...) (p. 237).

Assim, as práticas discursivas atravessam e são atravessadas por um saber que perpassa os diversos níveis e estruturas institucionais, criando possibilidades de readequação ao/do contexto, através da atualização do discurso, partindo das condições abertas no campo.

Desta maneira, Foucault (1996) vai aprofundando sua análise através do entendimento das condições que possibilitaram o surgimento e permanência de determinadas práticas discursivas, através da genealogia. Tal perspectiva possibilita a compreensão dos enunciados, ou melhor, da formação discursiva como construção histórica, valorizando as condições abertas no ambiente - características e necessidades existentes - que produzem ou permitem a emergência desta mesma prática discursiva como dispositivo de poder, já que: "A genealogia, como análise da proveniência está (...) no ponto de articulação do corpo com a história. Ela deve mostrar o corpo inteiramente marcado de história e a história arruinando o corpo" (Foucault, 1993, p. 22).

Assim, se a analítica interpretativa é possível conforme especificada acima - ela tem suas bases nas propostas arqueológica - que busca a análise da discursividade local - e genealógica - que busca as condições de emergência da formação discursiva que ali se apresenta. Entendo que a leitura de Foucault considera o sujeito sempre como efeito do discurso, ou melhor, de formações discursivas que emergem em meio a um jogo de forças que se atualizam a cada nova relação, a cada momento, e não de maneira linearmente evolutiva ao longo do tempo.

Neste artigo, viso à problematização da relação entre os métodos arqueológico e genealógico, como condição de possibilidade para a emergência daquilo que Rabinow e Dreyfus (1995) denominaram analítica interpretativa. Com este objetivo, faço uma introdução aos métodos arqueológico e genealógico e, posteriormente, tento considerar a terceira fase da teorização foucaultiana como resultado dos questionamentos que emergiram nas etapas anteriores e levam a pensar as condições de existência do homem enquanto sujeito moral.

\section{O DISCURSO EM FOUCAULT}

Em Foucault (1996), somos remetidos, a todo o momento, a uma complexa relação entre a realidade e o signo, não sendo este último apenas expressão simbólica da primeira, mas a própria; ou melhor, a primeira entra em uma relação de derivação quanto ao enunciado que lhe produz. O discurso, portanto, não existe em outra dimensão senão a do real, já que é no campo dos enunciados que toda realidade se manifesta.

$\mathrm{O}$ autor parte do pressuposto de que toda sociedade, como construção histórica, tem seu suporte em práticas discursivas que a atravessam, criando assim as possibilidades para que surja através de uma formação discursiva própria, porém inter-relacionada com o macrocontexto.

Assim, partindo do pressuposto de que toda sociedade engendra discursos, porém tem sua produção controlada, selecionada, organizada e redistribuída por certo número de procedimentos que têm por função evitar seus poderes e perigos, Foucault, em textos como: "As palavras e as coisas", "A arqueologia do saber", "A ordem do discurso" e "História da sexualidade", identifica e, posteriormente, atualiza procedimentos internos $\mathrm{e}$ externos que regulam o acontecimento discursivo.

Tais procedimentos foram definidos a partir de alguns princípios que identificam e analisam os mecanismos que criam as condições de possibilidade para que o discurso seja valorizado como verdade ou excluído de uma determinada formação discursiva.

Os procedimentos internos regulam o discurso de dentro, através de princípios de classificação, de 
seleção, de ordenação e de distribuição. Tais procedimentos internos ao discurso seriam: em primeiro lugar, o comentário, segundo o qual se pode supor que há, nas unidades discursivas, uma espécie de desnivelamento entre os discursos; ou seja, existem os discursos corriqueiros, que passam com o ato mesmo que os pronunciou, e os discursos que estão na origem de certo número de atos novos de fala que os retomam, transformam ou falam deles, discursos que permanecem através de sua atualização.

Tal atualização Foucault nomeou como princípio de deslocamento. Sua materialização se dá pela utilização de discursos que, indefinidamente, para além de sua formulação, são ditos, permanecem ditos e estão ainda por dizer, já que, esta "substituição" não é estável, constante ou absoluta, pois não cessa de se modificar com o tempo.

Destarte, partindo do discurso que é entendido como multiplicidade aberta, os acasos são transferidos pelo princípio de deslocamento, ou seja, o novo não está no que é dito, mas no acontecimento de sua volta, que assume, no comentário, um paradoxo: dizer pela primeira vez aquilo que já havia sido dito e repetir aquilo que nunca havia sido pronunciado.

Cabe, ainda, salientar que tal desnível entre o discurso primeiro e o segundo - seu comentário - tem por atribuição dois papéis solidários: por um lado abre a possibilidade de construção múltipla e permanente a partir do texto primeiro; por outro lado, o comentário não possui nenhum outro papel senão o de dizer aquilo que estava articulado silenciosamente no texto que lhe deu origem.

O segundo procedimento é do autor, que, regido pelo princípio da rarefação, agrupa o discurso como unidade e origem de suas significações, como foco de sua coerência. Pede-se que o autor se responsabilize pela unidade do texto a ele delegada, que sustente o sentido que o atravessa, que o articule com sua vida. Para Foucault (2001a), o autor provoca a inserção social do texto através da elaboração dos nós de coerência textual que o ligam à formação discursiva.

$\mathrm{O}$ terceiro procedimento é a disciplina, princípio que, opondo-se ao autor e ao comentário, permite que se construa - através da submissão a um jogo restrito, já que as disciplinas se definem por um domínio de objetos - um conjunto de métodos, um corpus de proposições consideradas verdadeiras, um jogo de regras e definições, de técnicas e instrumentos, que se constituem numa espécie de sistema anônimo à disposição de quem quer ou pode servir-se dele, sem que seu sentido ou validade estejam ligados a quem lhe provocou a emergência.
Assim, o que é suposto na origem não é um sentido a ser descoberto, mas aquilo que é requerido para a construção de novos enunciados, sendo imprescindível a uma disciplina a possibilidade de formulação constante de novas proposições.

Não obstante, para que uma proposição pertença a uma disciplina, em um domínio especifico, é necessário que ela responda a condições bastante estritas e complexas: precisa dirigir-se a um plano de objetos determinados e deve se inscrever em um horizonte teórico singular.

Segundo Foucault, vêem-se normalmente nestes princípios as condições para a emergência de novos discursos; porém, desconsidera-se muitas vezes a sua principal função:

Tem-se o hábito de ver na fecundidade de um
autor, na multiplicidade dos comentários, no
desenvolvimento de uma disciplina, como
que recursos infinitos para a criação dos
discursos. Pode ser, mas não deixam de ser
princípios de coerção; e é provável que não
se possa explicar seu papel positivo e
multiplicador, se não se levar em
consideração sua função restritiva e
coercitiva (Foucault, 1996, p. 36).

Já os procedimentos externos de regulação do discurso foram definidos a partir de sistemas de exclusão que cumprem sua função estratégica, identificando e analisando as condições de possibilidade para que o discurso seja valorizado como verdade ou excluído de uma determinada formação discursiva. Voltam-se para dominar $o$ acontecimento aleatório, sendo, ao mesmo tempo, formadores do ambiente em que se inscrevem e atravessados por este mesmo meio institucional. Tais procedimentos externos são definidos por Foucault como: ciclo da interdição, separação e rejeição e vontade de verdade.

O ciclo da interdição é definido por três etapas. A primeira é a proibição, que inibe o aparecimento sob pena de supressão, jogando com a alternativa entre duas inexistências. A segunda é a censura, onde a interdição toma três formas: afirmar que não é permitido, impedir que se diga e negar que exista, ligando o inexistente, o ilícito e o informulável e tornando-os a cada um, princípio e efeito do outro:

(...) do que é interdito não se deve falar até ser anulado no real; o que é inexistente não tem direito à manifestação nenhuma, mesmo na ordem da palavra que enuncia sua inexistência; e o que deve ser calado 
encontra-se banido do real como o interdito por excelência (1993b, p. 82).

A terceira é a unidade do dispositivo, onde o poder atravessa os vários níveis, regulando-os de alto a baixo.

Mas há outras formas de problematizar e esclarecer o discurso. Por exemplo, na separação e rejeição, tem-se uma divisão valorativa que atravessa as diversas formações discursivas; selecionando, classificando, habilitando ou excluindo os enunciados. Tal valoração provoca a exclusão de determinados discursos, que, a partir da separação, são vistos como divergentes, ganham status diferenciado e podem ser avaliados como acima do normal ou como não merecedores de escuta. De qualquer modo, tais discursos divergentes, investidos pela razão, são rejeitados, tornando-se nulos e sem acolhida em determinada formação discursiva; enfim, é o afastamento da palavra que está fora do discurso verdadeiro.

Por último, a vontade de verdade, que se caracteriza por ser um tipo de separação historicamente construída, define a forma geral de materialização de nossa vontade de saber; com suporte institucional. Esta consiste dos planos de objetos a conhecer, dos métodos para efetivar o conhecimento, das funções e posições do sujeito cognoscente, do desejo de conhecer, verificar, comprovar cientificamente, e, principalmente, dos investimentos materiais, técnicos, instrumentais do conhecimento em relação ao modo como o saber é aplicado em uma sociedade.

Em relação aos procedimentos externos citados acima, Foucault atribui à vontade de verdade o norte de condução, pois este procura retomar os anteriores, por sua própria conta, para, ao mesmo tempo, modificá-los e fundamentá-los.

À medida que a vontade de verdade atravessa o poder e o saber, produz através deles uma verdade que não cessa de se reforçar e de se tornar mais profunda, enquanto os demais procedimentos externos, atravessados pela vontade de verdade, tornam-se mais frágeis e incertos. Assim, os princípios externos põem em pauta o desejo e o poder.

Por conseguinte, existem a proposta de uma verdade ideal como lei do discurso que predomina em determinado espaço e uma racionalidade imanente como princípio de seu desenvolvimento, que conduz a uma ética do conhecimento que só promete a verdade ao próprio desejo de verdade, o qual se realiza unicamente através do poder de pensá-la.

Desta forma, o discurso se caracterizaria por pôr em jogo as estruturas mesmas da linguagem enquanto produção de sentido, do que pode surgir a crença no sujeito como fundante e no significante.

Sobre isto, Foucault (1996) assinala:

(...) sob esta aparente veneração do discurso, sob essa aparente logofilia, esconde-se uma espécie de temor. Tudo se passa como se interdições, supressões, fronteiras e limites tivessem sido dispostos de modo a dominar, ao menos em parte, a grande proliferação do discurso (p. 50).

Com vista a esta análise discursiva, Foucault propõe quatro noções que devem servir de princípios reguladores para a arqueologia, em substituição a quatro outros conceitos que, de modo geral, têm dominado a história tradicional das idéias:

- Noção de acontecimento: é o conjunto de forças presentes no meio e que possibilitaram a emergência de determinada prática, em substituição à criação ou ponto de origem da obra.

- Noção de série: é a análise em relação ao tema como multiplicidades determináveis historicamente, em substituição à unidade de uma obra como continuidade e estabilidade.

- Noção de regularidade: são regras do campo onde as singularidades se distribuem e se reproduzem, em substituição à originalidade, evitando recorrer à idéia de originalidade centrada em um indivíduo;

- Noção de condições de possibilidade: são alternativas abertas no campo como resultado das relações de força que definem as opções de emergência, em substituição à idéia de significação; esta última, tesouro indefinido dos significados ocultos.

\section{ARQUEOLOGIA E GENEALOGIA}

A arqueologia tem por propósito descrever a constituição do campo, entendendo-o como uma rede, formada na inter-relação dos diversos saberes ali presentes. E é exatamente nesta rede, pelas características que lhe são próprias, que se abre o espaço de possibilidade para a emergência do discurso.

Já a genealogia busca a origem dos saberes, ou seja, da configuração de suas positividades, a partir das condições de possibilidades externas aos próprios saberes; ou melhor, considera-os como elementos de um dispositivo de natureza essencialmente estratégica. Procura-se a explicação dos fatores que interferem na sua emergência, permanência e adequação ao campo 
discursivo, defendendo sua existência como elementos incluídos em um dispositivo político.

$\mathrm{Na}$ metodologia foucaultiana, a arqueologia e a genealogia se constituem como dois conjuntos complementares, sendo sua diferença não tanto de objeto ou de domínio, mas de ponto de ataque, de perspectiva e de delimitação.

Para Foucault (1996), a arqueologia

(...) procura cercar as formas da exclusão, da limitação, da apropriação (...); mostrar como se formaram, para responder a que necessidades, como se modificaram e se deslocaram, que força exerceram efetivamente, em que medida foram contornadas ( p. 60).

Por outro lado, o conjunto genealógico põe em prática outros princípios que se formaram através, apesar ou com o apoio da arqueologia:

(...) este concerne à formação efetiva dos discursos, quer no interior dos limites do controle, quer no exterior, quer, a maior parte das vezes, de um lado e de outro da delimitação. A crítica analisa os processos de rarefação, mas também de agrupamento e de unificação dos discursos; a genealogia estuda sua formação ao mesmo tempo dispersa, descontínua e regular (Foucault, 1996, p. 65$66)$.

Estas duas tarefas são não somente complementares, mas também inseparáveis: por um lado, as formas da seleção, adequação, reagrupamento, alteração ou exclusão operam submetendo o discurso ao controle; por outro, este dá sustentação à análise da proveniência, que deve levar em conta os mecanismos e estratégias postos em prática nas relações de força e, principalmente, os limites e regras que emergem deste dispositivo político e se objetivam através das regularidades discursivas que delimitam o espaço de existência do discurso.

Neste ponto, Foucault entende a genealogia como uma atividade de investigação trabalhosa, que procura os indícios nos fatos desconsiderados, desvalorizados e mesmo apagados pelos procedimentos da história tradicional, na busca da confirmação de suas hipóteses.

A atividade genealógica requer, indispensavelmente, a busca da singularidade dos acontecimentos, sobretudo naquilo que não participa da história, como "(...) os sentimentos, o amor, a consciência, os instintos" (Foucault, 2000 b, p. 260), fazendo emergir o entendimento sobre os espaços onde desempenharam papéis distintos e/ou foram excluídos do discurso verdadeiro.

Trata-se, nesta análise, de ativar os saberes locais, não legitimados ou valorizados pelo discurso verdadeiro, que, ao ocupar um lugar qualificado como científico, ordena, hierarquiza, classifica e depura os diversos saberes, em nome dos direitos desta ciência detida por alguns.

A genealogia escuta a história, prestando atenção a seus acasos e suas descontinuidades, pois se há algo a decifrar, algum segredo a desvendar, é que as coisas não têm essência, ou melhor, a suposta essência foi deliberadamente construída, a partir de situações especificas, contextualizadas histórica e socialmente. A própria razão nasceu do acaso, da paixão dos cientistas, de sua busca incessante de verdade, de suas discussões fanáticas, enfim, de sua vontade de saber e de sua necessidade em suprimir as paixões. O que dá forma a todas as coisas emergentes não é uma suposta identidade baseada na origem, mas a discórdia existente entre as coisas (Foucault, 1993a).

A genealogia propõe demarcar os acidentes e os acasos, sejam eles ínfimos desvios ou inversões completas que vieram a dar origem ao que hoje existe e possui valor; propõe que, na emergência do que somos, não existem a verdade e o ser, mas a exterioridade do acidente.

Cabe salientar que as normas daí emergentes são em si mesmas vazias, não-finalizadas e violentas; contudo, são exatamente aquilo por que se luta. É a história que define as condições para a produção do sujeito, que, ao se produzir, reproduz a história.

A genealogia ou a análise da proveniência está no ponto de articulação do corpo com a história. Neste ponto, Foucault (1993a) indaga a respeito dos discursos verdadeiros, quando submetidos à análise genealógica: "Que convicção lhe resistiria? Mais ainda, que saber?" (p. 21)

Outra característica da história efetiva é sua noção de que todo saber sempre será perspectivo, aceitando por essa via a injustiça pressuposta no olhar parcial que a embasa. Ele parte de um determinado ângulo e, de forma deliberada, movimenta-se com o fim de apreciar, de avaliar, de dizer sim ou não. Enfim, este olhar sabe para o que olha, assim como sabe o lugar de onde olha.

Cabe salientar que o método genealógico não busca a destruição do que somos. Não se trata de uma avaliação do passado em nome de uma nova verdade, mas de uma análise do que somos, enquanto atravessados pela vontade de verdade. Assim, a genealogia seria o estudo das formas de poder: “(...) na sua multiplicidade, nas suas diferenças, na sua 
especificidade, na sua reversibilidade: estudá-las, portanto, como relações de força que se entrecruzam, que remetem umas às outras, convergem ou, ao contrário se opõem (...)” (Foucault, 1997, p. 71).

Convém sublinhar que a parte arqueológica da análise liga-se aos sistemas de recobrimento do discurso, é o método próprio à análise da discursividade local. Porém, a parte genealógica se detém na análise da formação efetiva do discurso busca entendê-lo em seu poder de constituir domínios de objetos através dos quais se poderiam afirmar ou negar proposições verdadeiras ou falsas; enfim, é a tática que, partindo da discursividade local, ativa os vários saberes através da crítica à sujeição que ali emerge (Foucault, 2000c).

Vista a arqueologia sob este aspecto, “(...) partindo do interior, Foucault, enquanto arqueólogo, pode retroceder no discurso analisado e tratá-lo como um discurso objeto. A arqueologia ainda isola e indica a arbitrariedade do horizonte hermenêutico do significado" (Rabinow \& Dreyfus, 1995, p. 118).

\section{A SUBJETIVAÇÃO}

Se, depois da saída de "A vontade de saber", Foucault fica num impasse, não é devido à sua maneira de pensar o poder: é, antes, porque descobriu o impasse em que o próprio poder nos coloca, na nossa vida como no nosso pensamento, a nós que nos debatemos com ele nas nossas mais ínfimas verdades. E só haveria saída se o de-fora fosse apanhado num movimento que o desvia da morte. Seria como que um novo eixo, simultaneamente distinto do do saber e do do poder (Deleuze, 1998, p. 129-130).

Esse eixo não invalida os outros. Por um lado impede-os de ficarem fechados, entendendo a própria “(...) motivação psicológica não como a fonte, mas como o resultado de estratégias sem estrategistas (...)" (Rabinow \& Dreyfus, 1995, p.121). Tal resultado leva a disposições, táticas, técnicas e funcionamentos que emergem no interstício de uma rede de relações sempre tensas. Por outro lado, a análise proposta só é possível a partir da base fornecida pela arqueologia e pela genealogia, que se dirigem ao exame dos sistemas de recobrimento e das condições de formação dos discursos locais.

Essa condição possibilita a Foucault (1994) definir o terceiro eixo como "(...) o estudo dos modos pelos quais os indivíduos são levados a se reconhecerem como sujeitos (...)" (p. 10); ou seja, a compreensão sobre as maneiras pelas quais os indivíduos podem construir a experiência deles mesmos enquanto sujeitos, constituindo-se como tal.

Ganha importância, neste contexto, o conceito de técnicas de si, que se caracterizam como conjuntos formados por práticas que definem a estética da existência, ou seja, práticas reflexivas e voluntárias através das quais:

(...) os homens não somente se fixam regras
de conduta, como também procuram se
transformar, modificar-se em seu ser singular
e fazer de sua vida uma obra que seja
portadora de certos valores estéticos e
respondam a certos critérios de estilo
(Foucault, 1994, p.15).

AS PRÁTICAS DE SI

Foucault (1990) explicita seu entendimento sobre as práticas de si partindo da diferenciação entre os códigos morais e a moral. Apesar de os códigos morais serem explicitamente formulados, sua transmissão acontece de forma difusa, constituindo a moral enquanto jogo complexo de elementos que se compensam, corrigem ou mesmo se anulam em pontos específicos. Desta forma, possibilita a abertura de interstícios, onde as resistências são possíveis, abrindo o espaço de possibilidade para que o indivíduo se submeta mais ou menos completamente às regras de conduta, através de sua obediência ou resistência às interdições.

Tais espaços abertos - interstícios - emergem já com margens de variação ou transgressão possíveis das quais os sujeitos ou grupos que compõem o espaço discursivo têm noção mais ou menos clara, já que o sistema prescritivo está explícita ou implicitamente dado nas práticas vigentes. Foucault (1994) denominou este nível de fenômeno como moralidade dos comportamentos, diferenciando: as regras de conduta ou código moral propriamente dito, a conduta que se pode medir em relação a estas regras ou as condutas classificáveis de acordo com o código e a maneira pela qual é necessário conduzir-se. Esta última é definida como a forma pela qual o indivíduo constitui a si mesmo como sujeito moral, ao agir sob a influência de um código.

$\mathrm{O}$ indivíduo age de forma a operar como sujeito moral desta ação em relação aos códigos prescritivos que operam em sua cultura; porém, mesmo em um contexto rígido, existem várias maneiras de ser austero. Tais diferenças em relação às formas de ser fiel foram denominadas por Foucault como substância 
ética, e tratam da forma como o indivíduo se constitui como sujeito moral (Foucault, 1994).

Neste ponto, ganha importância o conceito de modos de sujeição, isto é, a maneira como o sujeito estabelece sua relação com tais regras, constituindo-se pela obrigação de colocá-las em prática. Para isto, se embasa na elaboração do trabalho ético sobre si mesmo, não somente tornando seus atos adequados a uma regra dada, mas também atualizando-se pelo exercício da prática moral

Saliente-se, não obstante, que a moralidade de um ato só é valorizada por sua inserção e pelo lugar moral que ocupa, o qual leva o indivíduo a ações e um modo de ser característicos que constituem o sujeito ético (Foucault, 1994).

Neste ponto de sua análise, Foucault retoma a importância da história, como fonte de subsídios quanto à construção de práticas de si que levam os sujeitos a reconhecerem-se, histórica e localmente, como possuidores ou não de conduta moral.

Tal história será a do estudo sobre a avaliação relativa à adequação das ações de indivíduos ou grupos, comparados aos valores propostos, e, principalmente, relativa à maneira como os sujeitos podem constituir-se como possuidores de moral, ou seja, como são chamados a construir a relação para consigo, a refletir sobre si, a conhecer-se, a examinarse, enfim, a autodecifrar-se. Isto é o que Foucault (1994) denomina como “uma história da 'ética' e da 'ascética', entendida como história das formas da subjetivação moral e das práticas de si destinadas a assegurá-la" (p. 29).

Sua proposta baseia-se na constituição moral, comportando dois aspectos fundamentais: os códigos de comportamento e as formas de subjetivação, instâncias caracterizadas pela inexistência singular ou por serem totalmente dissociadas uma da outra. Ao mesmo tempo, essas instâncias desenvolvem-se sob uma relativa autonomia, que varia conforme a valorização cultural dada ao código, em sua capacidade de ajustar-se e de cobrir os campos de comportamento, e conforme o processo de subjetivação e das práticas de si.

No caso de maior valorização do código moral, pode-se chegar a um código rígido, a que o sujeito deverá submeter-se, incondicionalmente, sob pena de punição; no caso inverso, ou seja, de maior valorização dos processos de subjetivação, a ênfase não estará no conteúdo da lei ou nas suas condições de aplicação, mas na relação consigo, sendo ela definida pela soberania de si sobre si mesmo.

Aqui, para Deleuze (2000), está a descoberta da estética da existência, ou seja, a regra facultativa do homem livre, que deriva do poder e do saber, mas que deles não depende, pois as práticas de si, ao tomarem forma, serão incorporadas nas relações de poder e saber, havendo uma reintegração a estes sistemas. Porém, esta relação para consigo, mesmo que parcialmente, sempre resistirá aos códigos e poderes, sendo esta a própria noção de poder em Foucault quando este diz que não existe poder sem resistência.

Assim, ao pronunciar-se sobre as práticas de si, Foucault (1994) esclarece sobre sua opção:

Daí a opção de método que fiz (...) manter em mente a distinção entre os elementos de código de uma moral e os elementos de ascese; não esquecer sua coexistência, sua relativa autonomia, nem suas diferenças possíveis de ênfase; levar em conta tudo que parece indicar, nessas morais, o privilégio das práticas de si, o interesse que elas podiam ter, o esforço que era feito para desenvolvê-las, aperfeiçoá-las, e ensiná-las, o debate que tinha lugar a seu respeito (p. 30).

\section{HERMENÊUTICA}

Para Foucault, não há nenhuma essência humana a ser resgatada, assim como não existe nenhuma verdade interpretável sob o discurso, pois toda hermenêutica pressupõe uma verdade a ser mostrada por um suposto saber. Da mesma forma, noções como as de unidade e identidade, quando confrontadas com a proposta nietzschiana (não há pretensão de esclarecer ou trabalhar as relações entre a genealogia em Nietzsche e em Foucault, neste texto), ficam diluídas, por suporem sempre um pretenso Eu.

Assim, o conhecimento como derivado da vontade de saber é uma construção que resulta não de instintos básicos ou naturais, mas de confrontos, onde cada instinto deseja instituir como norma a sua perspectiva para todos os outros, ou nas palavras de Nietzsche (1998)

Uma ordem de direito concebida como geral
e soberana, não como meio na luta entre
complexos de poder, mas como meio contra
toda luta (...) toda vontade deve considerar
outra vontade como igual, seria um princípio
hostil à vida, uma ordem destruidora e
desagregadora do homem, um atentado ao
futuro do homem, um sinal de cansaço, um
caminho sinuoso para o nada (p. 65 ).

$\mathrm{O}$ ato discursivo, nesta perspectiva, sempre se impõe, pois nunca é desprovido de vontade de verdade. Interpretar, portanto, não é apenas encontrar 
um significado comum e universal para determinado signo, mas, principalmente, imprimir e produzir uma verdade que submete o outro.

Rabinow e Dreyfus (1995) entendem que a interpretação - como definida anteriormente - só pode advir de alguém que partilhe o ambiente do ator, desconsiderando as práticas sociais e resultando em uma leitura da coerência destas práticas; porém não pretende revelar seu significado intrínseco, e é neste sentido que o método foucaultiano é interpretativo, mas não hermenêutico.

Assim, a genealogia - termo tomado de Nietzsche - é definida por Foucault como uma metodologia que visa analisar o poder em seu contexto prático, ligado às condições que permitiram sua emergência, fazendo a análise histórica das condições políticas de possibilidade dos discursos; desta forma, o genealogista não busca a origem, mas a proveniência.

\section{REFERÊNCIAS}

American Psychological Association. (2001). Manual de publicação da American Psychological Association. Porto Alegre: Artmed.

Deleuze, G. (1998). Foucault. Lisboa: Veja

Deleuze, G. (2000). Conversações. São Paulo: Editora 34

Foucault, M. (1987). Vigiar e punir. Petrópolis: Vozes.

Foucault, M. (1990). Hermeneutica del sujeto. La Piqueta: Madrid. Foucault, M. (1993 a). Microfísica do poder. Rio de Janeiro: Graal.

Foucault, M. (1993 b). História da sexualidade I - a vontade de saber. Rio de Janeiro: Graal.
Foucault, M. (1994). História da sexualidade II - o uso dos prazeres. Rio de Janeiro: Graal.

Foucault, M. (1995). O sujeito e o poder. Em P. Rabinow \& H. Dreyfus, Michel Foucault - uma trajetória filosófica: para além do estruturalismo e da hermenêtica (pp. 231-249). Rio de Janeiro: Forense Universitária.

Foucault, M. (1996). A ordem do discurso. São Paulo: Edições Loyola.

Foucault, M. (1997). Resumo dos cursos do Collège de France (1970-1982). Rio de Janeiro: Jorge Zahar Editor.

Foucault, M. (2000). A arqueologia do saber. Rio de Janeiro: Forense Universitária.

Foucault, M. (2000 a). As palavras e as coisas. São Paulo: Martins Fontes.

Foucault. M. (2000 b). Arqueologia das ciências e história dos sistemas de pensamentos. Rio de Janeiro: Forense Universitária.

Foucault, M. (2000 c). Em defesa da sociedade. São Paulo: Martins Fontes.

Foucault, M. (2001). A verdade e as formas jurídicas. Rio de Janeiro: Nau Editora.

Foucault, M. (2001 a). Estética: literatura e pintura, música e cinema. Rio de Janeiro: Forense Universitária.

Nietzsche, F. (1998). Genealogia da moral. São Paulo: Companhia das Letras.

Rabinow, P. \& Dreyfus, H. (1995). Michel Foucault - uma trajetória filosófica: para além do estruturalismo e da hermenêutica. Rio de Janeiro: Forense Universitária.

Recebido em 30/01/2004 Aceito em 30/08/2004

Endereço para correspondência: Rogério Fae: Rua Dra. Rita Lobato, 194, apto. 204, Praia de Belas, CEP 90110-040, Porto Alegre-RS. E-mail: rogerfae@ @erra.com.br 